\title{
Editorial
}

\section{Components of a geriatric medical service: view from the UK}

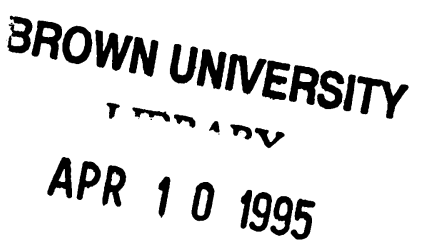

There is continuing debate as to the best means of delivering a geriatric medical service. Most would broadly agree that older people should be provided with comprehensive acute medical treatment, effective multidisciplinary rehabilitative therapy, and that for those who need it facilities should be provided for quality long-term care. Who takes responsibility for the various components and in what setting they occur, is more controversial.

\section{Acute medical care}

Effective acute medical care for elderly patients should be sited in local general hospitals, or at the least, there should be easy access to their investigative and therapeutic facilities. The style of acute geriatric medical service offered varies between localities and is still a matter of debate (see box).

\section{INTEGRATION MODEL}

Proponents of integration with general medicine argue that this is the best way of ensuring that elderly patients receive access to the skills of other specialties without the risk of an ageist approach being taken., ${ }^{1,2}$ Others would argue that this can be achieved without full integration with general medicine provided that there is good cooperation between disciplines. ${ }^{3}$ Those in favour of integration also argue that it fosters a more widespread positive approach to older people from nursing and medical staff. ${ }^{4}$ In the current climate in the UK of pressure to reduce junior doctors' hours, shared rotas as occur on integrated firms provide an opportunity to achieve the reduction in hours but with a compensatory increase in the workload per unit time. One possible disadvantage of this approach is that in reality it may be difficult to establish a keen multidisciplinary team on all acute medical wards. Indeed the simple measures, such as attention to bed and chair height, which were vital in achieving a therapeutic environment in the early days of geriatric medicine, could be lost. Obviously the onus is on the physician with special responsibility for elderly patients to enthuse and train team members in the necessary skills. Another possible disadvantage with the integrated model is that some elderly patients will remain under the care of general physicians and unrecognised rehabilitative needs might be missed.

AGE-RELATED MODEL

An age-related policy has the advantage of being easy to administer, particularly if there are sufficient designated geriatric medical beds to accommodate all of the admissions

Acute medical care for the elderly

Models:

- integrated with general medicine

- age-related policy

- needs-related policy over the defined age. It is argued that this type of policy treats patients in an arbitrary fashion without reference to their physiological age, resulting in patients with single system disorders being inappropriately looked after by consultants in geriatric medicine. The higher the age limit set, the more likely the patient is to have multiple pathology and rehabilitative requirements and thus to avoid this problem. It is essential that there is good interdisciplinary liaison and flexibility to allow patients under the defined age to be cared for by the geriatric team if demanded by their needs.

NEEDS-RELATED MODEL

Selective needs-related policies may run into problems where physicians differ in their perception of what is 'geriatric'. Whitaker and Tallis ${ }^{5}$ demonstrated that $42 \%$ of people classified as geriatric patients were not considered to be so by general physicians. Unless there are clear definitions and good inter-team communications, patients who would benefit from the early intervention of the geriatric team may be missed or referred too late. The advantage of both age-related and needs-related policies is that patients are cared for on designated wards with nursing, medical, and paramedical staff who are enthusiastic about elderly patients and keen to promote a therapeutic environment.

\section{Rehabilitation}

Rehabilitation can be defined as intervention between impairment and disability and between disability and handicap. ${ }^{6}$ Possible settings for this in a geriatric medical service are integrated acute and rehabilitation wards, specific rehabilitation wards, disease specific units, such as stroke units, and day hospitals. It is difficult to split acute and rehabilitative care as these usually occur concurrently in the same individual. However, whatever the setting, there must be a coherent policy and defined goals. It is likely that future research will attempt to tease out the elements of our current rather global rehabilitative packages to ascertain which produce the desired therapeutic effect. It is argued that concentrating on rehabilitating a small number of patients who would otherwise become long-stay is the key to increasing turnover in a geriatric unit.?

\section{Long-stay care}

There is much debate about the 'where' and 'how' of long-stay care for elderly people. What has not changed is the imperative initiated by Marjorie Warren to ensure that the elderly chronic sick are properly assessed for rehabilitative potential before being admitted for long-stay care. ${ }^{8}$ Neither is it in doubt that the long-stay care provided should be of a high quality both in terms of environment and staff training in the management of such problems as continence, falls, pressure sore prevention, and so on. ${ }^{9}$

The debate centres around who takes responsibility for patients in long-stay care beds. ${ }^{10}$ Whilst some general 
practitioners may have the resources in terms of expertise and time to provide quality assessment and management of such patients, most will not. It is desirable that someone with skills in the care of older patients has overall responsibility for patient care and for the performance of the establishment. If long-stay care is diverted in a fragmented fashion to the private sector this will be difficult to achieve. The skills of consultants in geriatric medicine may also be needed at a national level for the strategic planning of long-stay care. ${ }^{11}$ How such care is funded is controversial. ${ }^{12}$ Some have argued that all long-stay care, including hospital, should be means tested and paid for by the patient. ${ }^{13}$

\section{'Community' geriatricians}

With the Community Care Act now in force, good liaison between the hospital-based geriatric, and the community services is essential. It has been proposed that a new breed of consultant might emerge - the consultant community physician in geriatric medicine ${ }^{14}$ It is better to envisage a consultant in geriatric medicine with a special interest in the community, as the physician would work primarily in the community but have access to hospital beds and be a full member of the local hospital-based team, with responsibilities for rehabilitation, continuing care, and liaison with primary care and social services. It is already known that there is a heavy burden of chronic illness in local authority homes, ${ }^{15}$ and that patients admitted as emergencies to local authority residential care may have medical

1 Evans JG. Aging and rationing. BMf 1991; 303: 869-70.

2 Forbes CD. Relationships of internal medicine and geriatrics: a new beginning. Scott Med $\mathcal{Y}$ 1990; 35: 67 .

3 Primrose WR, Scott CJ. Aging and rationing. (letter) BMF 1991; 303: 1269. Evans JG. Integration of geriatric with general medical services in Newcastle. Lancet 1983; 1 : 1430-3.

5 Whitaker J, Tallis R. Misplaced elderly patients in hospital: clarifying responsibilities. Health Trends 1992; 24: 15-7.

6 Tallis R. Rehabilitation of the elderly in the 21 st century. $\mathcal{F}$ Coll Physicians Lond 1992; 26: 413-22.

7 Millard PH. A case for the development of departments of gerocomy in all district general hospitals. $\mathcal{F} R$ Soc Med 1991; 84: 731-3.

8 Warren $M$. Care of the chronic sick: a case for treating the chronic sick in blocks in a general hospital. BMf 1943; 2: 822-3.

9 A summary of a report of the Royal College of Physicians and the British Geriatrics Society. High quality long-term care for elderly people. $\mathcal{I} R$ Coll Physicians Lond 1992; 26: 130-2.

\section{Components of a geriatric medical service}

- elderly patients must have access to good acute medical facilities

- good liaison between all hospital and community services is essential

- rehabilitation must be structured to achieve defined goals

- patients should be fully assessed for rehabilitative potential before being admitted to any form of long-stay care

- physicians with expertise in the care of elderly patients should supervise long-stay care facilities

problems more appropriately assessed and treated by a geriatrician. ${ }^{16} \mathrm{~A}$ physician with special responsibilities in the community would be in a good position to assume this role.

IR HASTIE, M COTTEE, E SMITH, D MUKHERJEE, D AMES, T KWOK, P KIST, J LIDDLE, H POWELL, R TOZER Senior Registrar Training Group, Division of Geriatric Medicine, St George's Hospital Medical School, London, UK

Correspondence to Dr IR Hastie, Division of Geriatric Medicine, St George's Hospital Medical School, London SW17 ORE, UK

10 Millard PH. The seven principles of planning geriatric medical services. Health Hygiene 1993; 14: 95-8.

11 British Geriatrics Society. Specialist advice and long-term care - a policy. London: British Geriatrics Society, 1993.

12 Editorial. Long-term care in the UK: do we need it, does it matter, who will pay? Lancet 1992; 339: 96-7.

13 Kellett J. Long-term care on the NHS: a vanishing prospect. BMF 1993; 306: 846-8.

14 British Geriatrics Society. Community geriatrician. London: British Geriatrics Society, 1993.

15 Gosney M, Tallis R, Edmond E. The burden of chronic illness in local authority residential homes for the elderly. Health Trends 1991; 22: 153-7.

16 Brooks R, Ritch A, Lismore J, Barford A. Do social admissions exist: a clinical study of emergency admissions into residential care in Birmingham. Health Trends 1990; 22: 67-70. 